AIAA-2000-4090

\title{
SIMULATION OF AIRCRAFT LANDING GEARS WITH A NONLINEAR DYNAMIC FINITE ELEMENT CODE
}

\author{
Karen H. Lyle, Karen E. Jackson ${ }^{\dagger}$, and Edwin L. Fasanella ${ }^{\ddagger}$ \\ US Army Vehicle Technology Directorate, Hampton VA 23681
}

\begin{abstract}
Recent advances in computational speed have made aircraft and spacecraft crash simulations using an explicit, nonlinear, transient-dynamic, finite element analysis code more feasible. This paper describes the development of a simple landing gear model, which accurately simulates the energy absorbed by the gear without adding substantial complexity to the model. For a crash model, the landing gear response is approximated with a spring where the force applied to the fuselage is computed in a user-written subroutine. Helicopter crash simulations using this approach are compared with previously acquired experimental data from a full-scale crash test of a composite helicopter.
\end{abstract}

\section{INTRODUCTION}

An important aspect of crashworthiness research is the demonstration and validation of analytical/computational tools for accurate simulation of airframe structural response to impacts. Crash simulation codes can be used during the airframe design phase to certify seats and aircraft, to predict seat and occupant response to impact with the probability of injury, and to evaluate numerous crash scenarios not economically feasible with full-scale crash testing.

Previously, rotorcraft and aircraft crash simulations were performed using semi-empirical kinematic codes such as KRASH [1]. The aircraft model typically contained less than 100 elements and was comprised of lumped masses, beams, and springs with user-defined crush properties based on experimental data. These models required significant engineering effort to reduce a complex aircraft structure to a simple mass-beam-spring model. Such models can provide significant information regarding overall aircraft dynamics. However, these models are not sufficient for detailed structural analysis. In addition, significant component testing is required to generate experimental data to describe the structural crush characteristics of the springs.

Technology advances have enabled the simulation of aircraft and spacecraft crashes in a reasonable time using detailed finite element models. These models can be executed in a nonlinear transient dynamic finite element code, such as LS-DYNA [2], MSC.Dytran [3], and PAM-CRASH [4]. These codes are commercial products based on the well validated, public domain code DYNA3D developed at Lawrence Livermore National Laboratories. Although the duration of an actual crash may be several seconds, the significant impact duration is typically less than 200 milliseconds. The CPU time of the simulation is dependent on the time step, the model size, and the total simulation time. CPU times from one day to one week on a high-end workstation are common to simulate the 200millisecond impact response of an aircraft.

Many aircraft now feature energy absorbing landing gears as part of the crash energy mitigation system. The accuracy of the prediction of the fuselage crash accelerations is directly dependent on the accuracy of the fuselage impact velocity and attitude. Therefore, any velocity reductions or changes in impact attitude resulting from the landing gear stroking must be modeled. However, the accelerations during landing gear stroking, but prior to fuselage impact, usually do not cause human injury or significant structural damage. For this reason, a method to model the landing gear effect without adding substantial

\footnotetext{
- Aerospace Engineer

' Aerospace Engineer, Associate Fellow

* Aerospace Engineer

This paper is declared a work of the U.S. Government and is not subject to copyright protection in the United States.
} 
complexity to the finite element model is needed. This paper highlights such a methodology.

The development of an innovative landing gear model for implementation in a nonlinear transient dynamic finite element code is described. The landing gear model was combined with a rigid rotorcraft fuselage model for the simulations presented in this paper. The results from the simulations are correlated with previously acquired experimental data.

\section{DESCRIPTION OF TEST}

The Sikorsky helicopter flight test article, developed under the U. S. Army's Advanced Composite Airframe Program (ACAP), see Figure 1, was recently crash tested at the NASA Langley Research Center Impact Dynamics Research Facility (IDRF), see Figure 2. This full-scale helicopter was designed and constructed in the 1980 's to evaluate the use of composite technology. The resulting ACAP airframe consisted of $82 \%$ composite materials, and the total weight and cost savings achieved based on the final design were $23 \%$ and $24 \%$, respectively. A systems approach was used in designing the helicopter for maximum crash protection, including energy absorbing landing gear, crushable subfloor structure, and load-limiting seats. However, the primary energy absorbing elements were the landing gear. The landing gear were designed to remove $80 \%$ of the energy for a vertical drop performed at the impact conditions of $38-\mathrm{ft} / \mathrm{s}, 10^{\circ}$ pitch, and $10^{\circ}$ roll as specified in Reference [5]. The main landing gear contained an aluminum honeycomb tube that would dissipate kinetic energy during a crash event through stable crushing, with a maximum crush stroke of 18 in.

The full-scale crash test of the helicopter was conducted on June 22, 1999 at the IDRF. Details regarding the helicopter, test conditions, instrumentation, etc., can be found in Reference [6]. The helicopter was suspended from the IDRF and dropped such that the impact attitude was 6.25 degrees pitch (nose-up) and 3.5 degrees roll (left), and the impact velocity was $-462 \mathrm{in} / \mathrm{sec}(-26$ $\mathrm{mph})$ vertical and $-384 \mathrm{in} / \mathrm{sec}(-21.8 \mathrm{mph})$ horizontal. The pendulum nature of the drop test induced a rotational pitch velocity of $9.6 \%$ (nose-up).

Onboard hardware included four energy-absorbing seats with anthropomorphic dummies. Approximately 90 channels of data, including 62 accelerometers, were collected at a $10 \mathrm{kHz}$ sampling rate using a digital data acquisition system. A schematic drawing of the helicopter indicating the locations of selected accelerometers used in the analytical/ experimental correlation is shown in Figure 3 . In general, high quality experimental data were obtained from the crash test. All acceleration data from the crash test were analyzed and checked for polarity errors, zerooffsets, and noise. Acceleration data in the vertical direction were integrated to obtain the vertical velocity change. The integration also provided a quality check of the data. Those channels in which the integrated velocity change varied greatly from the nominal vertical impact velocity were not used for the correlation with the analysis.

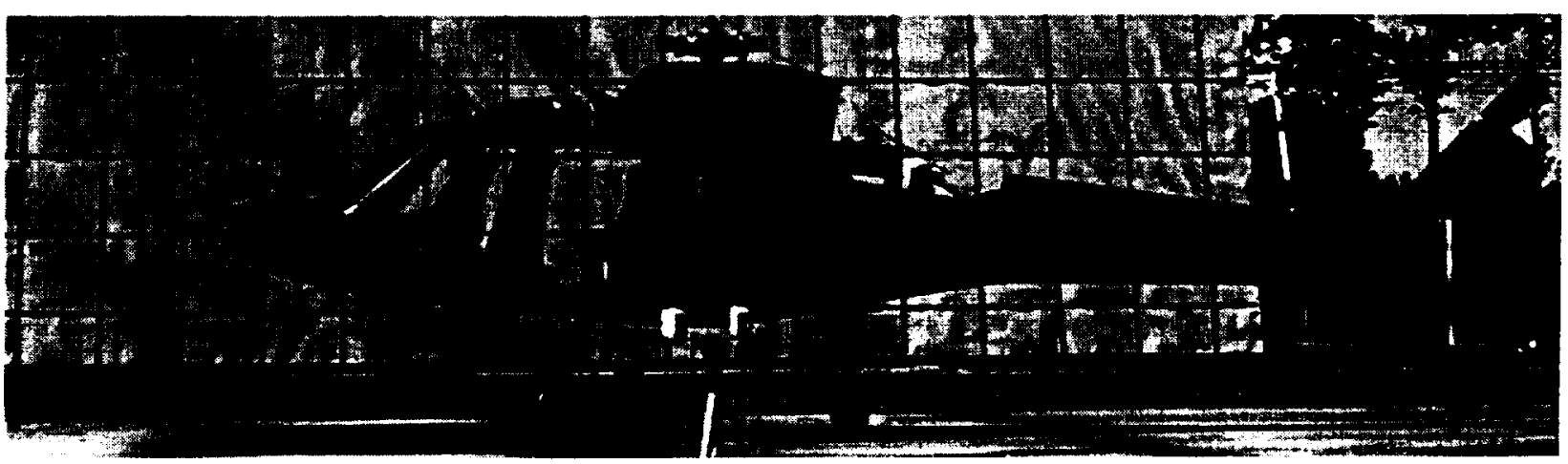

Figure 1. Photograph of ACAP helicopter at time of impact. 


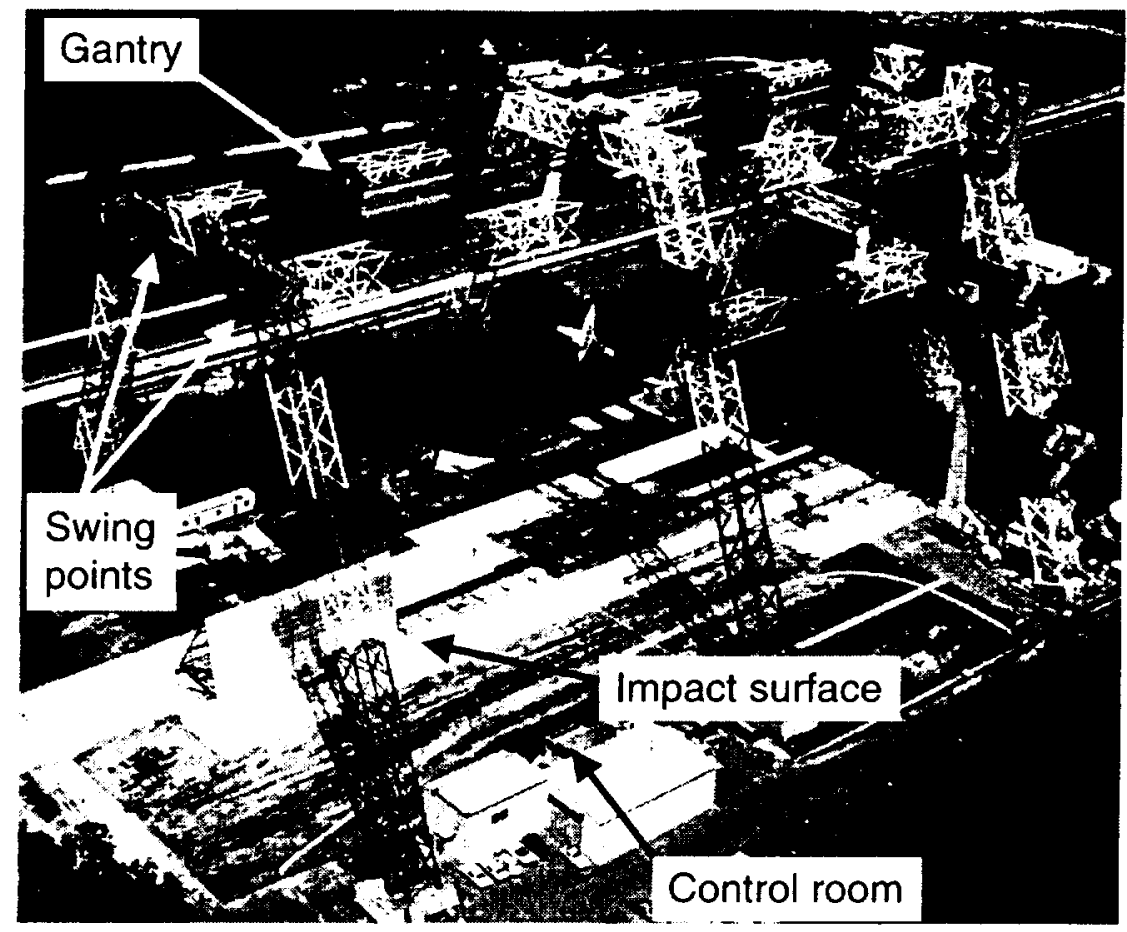

Figure 2. Schematic of NASA Langley Research Center Impact Dynamics Research Test Facility.
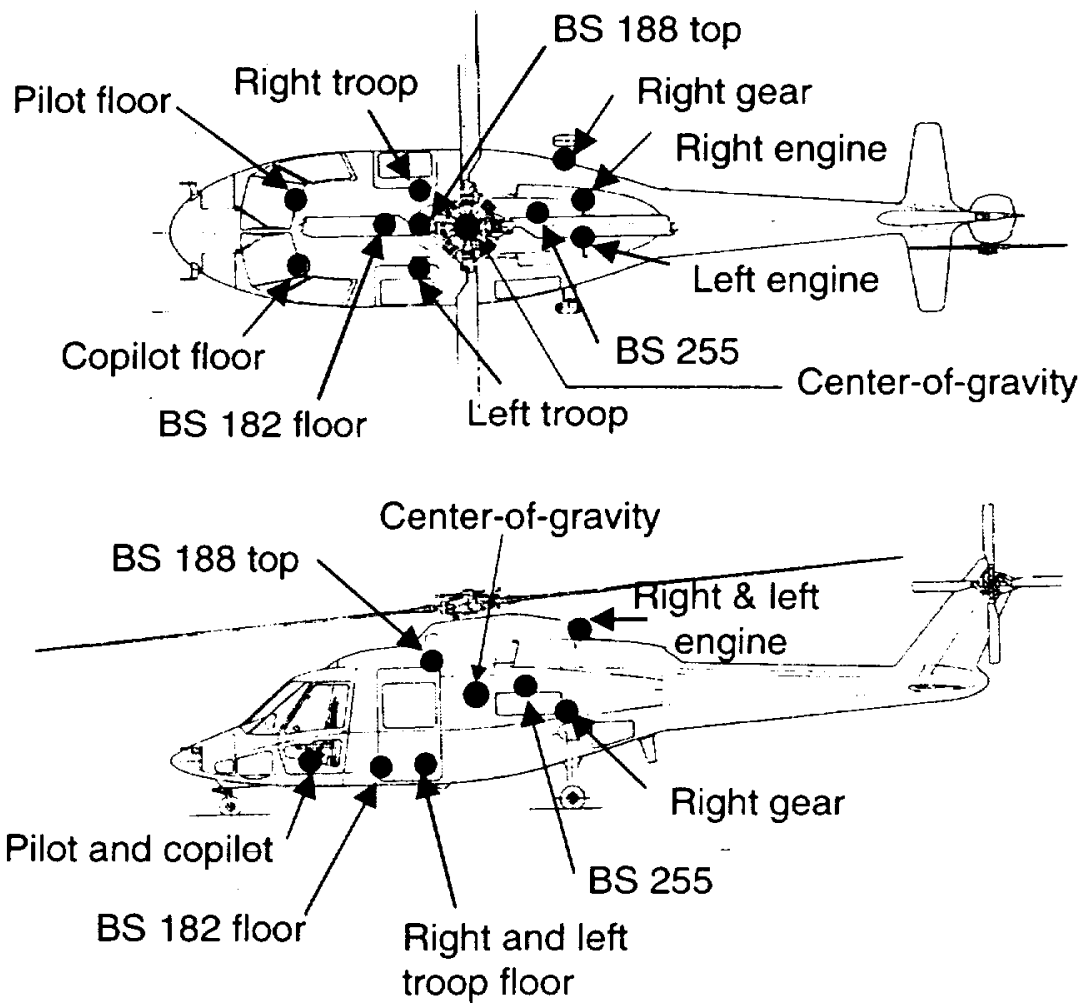

Figure 3. Schematic of selected accelerometer locations. 


\section{DEVELOPMENT OF CRASH FINITE ELEMENT MODEL}

A two-stage modeling approach was used to conduct the crash simulations using the nonlinear, transient dynamic, finite element code, MSC.Dytran. For impacts on hard surfaces, accurate simulation of the energy absorption behavior of the landing gear is imperative to accurately predict the impact response of the fuselage. The landing gear stroking not only reduces the fuselage impact speed, but can also change the impact attitude. The stroking of the landing gear, which can typically last 100 milliseconds, generally provides low acceleration leveis, and thus insignificant elastic deformations to the fuselage, as compared to the fuselage impact event. These facts enabled utilization of a rigid fuselage model during the landing gear stroking. Prior to fuselage contact, the nodal velocities and positions from the rigid simulation are then input into a flexible model. Correlations of the flexible fuselage model simulations with the experimental data are presented in Reference [7]. The time step for rigid models is typically an order of magnitude larger than that for the fiexible model, therefore the required clock time to perform a simulation is reduced by an order of magnitude. For the model presented here, the CPU time was reduced by a factor of eight. In addition, the rigid model made the introduction of the pitch angular velocity much easier.

\section{Landing Gear}

A schematic of the ACAP main landing gear as viewed aft of the aircraft is shown in Figure 4. The main gear were designed with a two-stage, energy absorption approach. For landings within the normal operational range, an oleo-pneumatic energy absorber has been incorporated. For severe or crash landings, additional energy may be absorbed with the stable crushing of an aluminum honeycomb column within the gear. The transfer from the oleo-pneumatic to the honeycomb stage is accomplished by shear pin failures based on a predetermined force. The orientation of the gear with respect to the fuselage remains nearly constant while the oleo-pneumatic stage is stroking. The angle with respect to the vertical, as shown in the figure, is 11.8 degrees. As the honeycomb crushes, the gear rotates outward an additional 20 degrees. The drag beam controls the gear rotation.

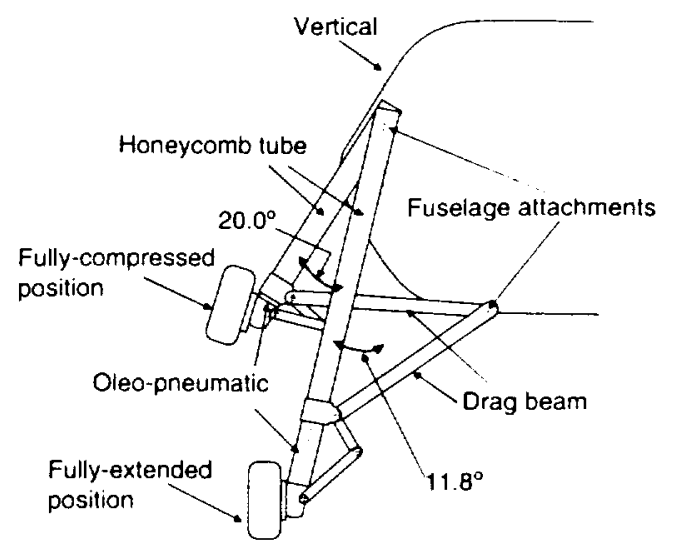

Figure 4. Schematic of ACAP landing gear looking aft.

To simplify the main landing gear mechanism as much as possible in the finite element model, the angle of the landing gear was fixed with respect to the aircraft vertical for the simulations. Therefore, the translational and rotational motions of the gear have been replaced with purely translation motion. The angle was determined by bisecting the angle through which the gear strokes, or $11.8^{\circ}+0.5 \times$ $20^{\circ}=21.8^{\circ}$, as shown in Figure 5. For a crash model, the landing gear force response can be approximated with a spring where the force is computed in a user-written subroutine. The "spring" force is dependent on the relative displacement and on the relative velocity of the connected nodes. Initially, it is assumed that the gear is fully deployed, as would be expected in a crash scenario.

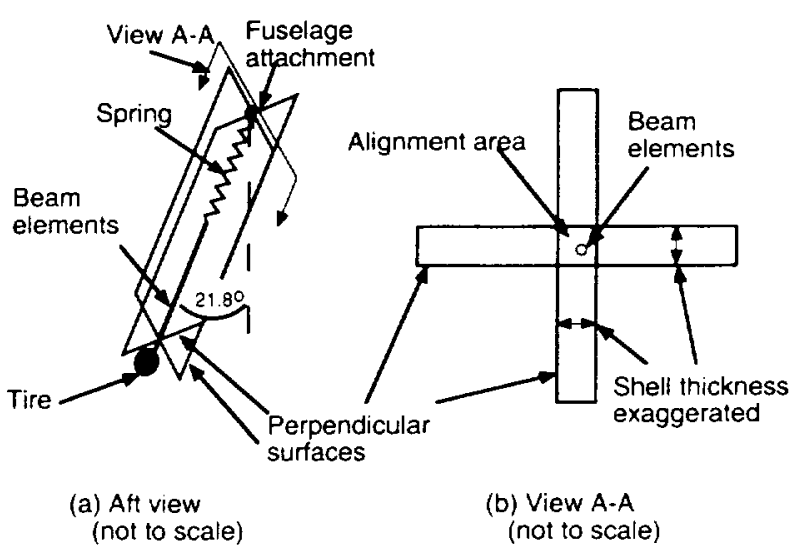

Figure 5. Schematic of landing gear in FEM. 
The original crashworthy nose gear had been removed and replaced with a non-crashworthy standard nose gear. Modifications were required to make the existing nose gear more crashworthy. The modified nose gear was modeled as a spring having a constant spring force of $8,000 \mathrm{lb}$. to represent the crush strength of the honeycombfilled aluminum tube that was inserted inside the gear.

Alignment of the gear spring relative to the aircraft can be a challenging modeling problem. A number of rigid joints, such as sliding, rotational, ball, and universal joints, are currently available as standard capabilities in commercial codes. However, these joints, which have only a small number of internal nodes (e. g., three), become unstable when large forces are applied - such as those experienced by the landing gear during a severe impact.

For this reason, these built-in joints were replaced in the model with a component containing several nodes and beam elements over which the forces are distributed, see Figure 5(a). Nodal alignment was accomplished by creating four contact surfaces on the two perpendicular plates. Each perpendicular plate was modeled with a rigid quadrilateral shell element. Rigid beams were used to connect the top rigid shell nodes to the fuselage at the attachment point. The spring force was defined in a user-written Fortran subroutine. The lower section of the gear was modeled with flexible beams attached to concentrated masses representing the tire. Each main gear model consisted of 40 nodes and 39 beam elements. The nose gear model consisted of seven nodes and six beam elements. The gear nodes were then constrained to remain within the intersecting region of the perpendicular shells, see Figure 5(b). The thickness of the alignment shells was set to provide sufficient stability without creating extremely large contact forces. For the results presented in this paper, the shell thickness was $0.010 \mathrm{in.}$

For simplicity of model development, the initial landing gear models were attached to a simple triangular rigid plate element, which approximated the fuselage. The aircraft mass, center of gravity, and moments of inertias were explicitly specified for the triangular element. Workstation simulations using this simple model are completed in a few minutes. The predicted nodal accelerations, velocities, and displacements at the gear attachment nodes are compared with the corresponding experimental data. These comparisons allow modifications to be quickly evaluated. Once adequate experimental/analytical correlation was achieved, the simple fuselage representation was replaced by a rigid fuselage model with the accurate geometry. The accurate geometry was needed to determine fuselage impact and to estimate the time to change from rigid to flexible simulation.

\section{Crash Finite Element Model}

The crash finite element model, see Figure 6, was developed from an existing modal vibration finite element model. Numerous modifications to the modal vibration model were required. These included: (1) reduction of the number of concentrated masses via mass distribution through material densities; (2) reduction of the number of different laminated composite shell and beam properties, where appropriate; (3) removal of very small elements, particularly in the tail, which are not relevant to the crash analysis; and (4) rediscretization to a finer mesh along the keel beams where significant crushing occurred. Additional details regarding the model conversion can be found in Reference [7].

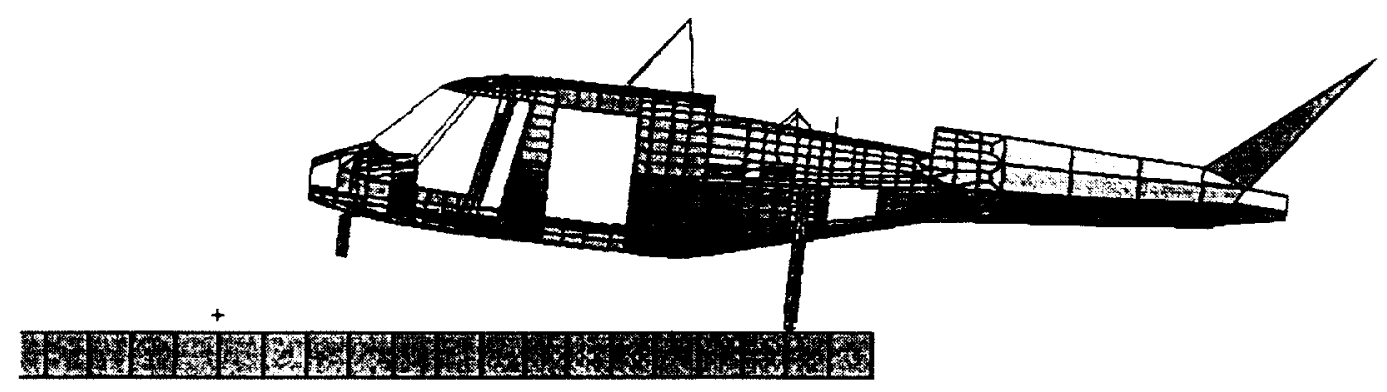

Figure 6. Crash finite element model.

$-5-$

American Institute of Aeronautics and Astronautics 
The impact surface was modeled with 250 hexahedral solid elements with fixed bottom nodes. The impact surface elements were assigned material properties typical of steel.

The initial impact velocities were determined from photographic motion picture analysis to be -462 in/sec vertical velocity, $-384 \mathrm{in} / \mathrm{sec}$ horizontal velocity and no lateral velocity. Due to the pendulum motion of the test, an initial angular velocity of 9.6-degrees/sec pitch was induced just before left gear contact. These fuselage velocities were implemented in the finite element code using the rigid model with MATRMRG1 and MATRIG options in MSC.Dytran. The impact attitude angles of 6.25 degrees pitch up and 3.5 degrees roll left were incorporate by rotating the impact plane with respect to the fuselage.

The resulting flexible fuselage model was composed of 4,128 nodes and 7,346 elements $(3,118$ beam and rod elements, 3,283 quadrilateral shell elements, and 695 triangular shell elements). These elements were defined using 34 properties in the flexible fuselage model. The 98 concentrated masses represented actual lumped masses on the test article. For the rigid model simulations presented in this paper, all the materials were combined into a MATRIG except for the landing gear beams and tire masses. The fuselage mass, center-of-gravity and moments of inertia were explicitly specified in the rigid fuselage model. These values were derived using MSC.Nastran [8], where the element and mass information from the crash model was converted to MSC.Dytran format. The final fuselage model weighed $7,998 \mathrm{lb}$ with a center-of-gravity at $x=203.7$ in., $y=0.0$ in., and $z=87.0$ in. The experimental test article weighed $7,832 \mathrm{lb}$ with a center-of-gravity location at $x-198$ in. and $z=100$ in. The experimental determination of the $z$ coordinate of the $\mathrm{cg}$-location is approximate due to the accuracy of the measurement set-up.

\section{CORRELATION OF SIMULATION RESULTS WITH EXPERIMENTAL DATA}

The rigid fuselage crash finite element model was executed in MSC.Dytran. The simulation results required nearly one hour CPU-time on a Sun Ultra 450 workstation to complete the $0.100-\mathrm{sec}$ problem time. The accuracy of the simulation results was evaluated through correlation with the experimental sequence of events and the velocities at specific locations.

Figure 7 shows the predicted spring forces representing the landing gears, which were applied to the fuselage model. Note that large forces are initially experienced due to the high velocity differential. The force of the main landing gear is removed at the time of the fuselage impact, $0.095 \mathrm{sec}$. The large initial forces for the main gear are not physical. These large forces did not significantly affect the rigid fuselage response, presumably due to the very short duration.

The simulation sequence of events, see Table 1 , was determined from the landing gear force curves. The test times were based on analysis of the high-speed film. Note that overall the correlation is very good with no more than four ms error. The longer time between the left and right gear contact for the simulation could be expected based on the simplified landing gear approach.

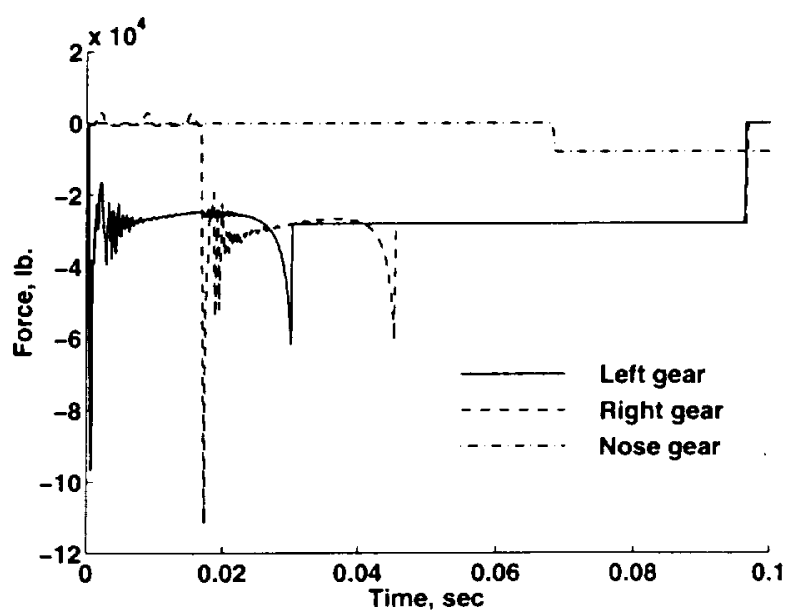

Figure 7. Predicted forces of the landing gear springs as a function of time.

Table 1. Timing of sequence of events for aircraft contact.

\begin{tabular}{|c|c|c|c|}
\hline Event & Pred., sec & Test, sec & Diff., sec \\
\hline Left gear & 0.0 & 0.0 & 0 \\
\hline Right gear & 0.016 & 0.012 & -0.004 \\
\hline Nose gear & 0.068 & 0.069 & +0.001 \\
\hline Fuselage & 0.095 & 0.0975 & +0.0025 \\
\hline
\end{tabular}

-6 - 
Although this paper focuses on the simulations prior to fuselage contact, the primary emphasis of the project was to accurately predict the input accelerations to the simulated occupants as well as retention of the overhead masses. Therefore, accuracy of the floor and large overhead mass accelerations was of utmost importance. Representative vertical accelerations at the pilot seat floor and right engine locations are shown in Figure 8 . The measured acceleration data was filtered with a $3^{\text {rd }}$ order Butterworth filter at $60 \mathrm{~Hz}$. The data were filtered forward and backward to eliminate phase shifts resulting from the filtering process. The maximum acceleration values for the curves occur well after the fuselage impacts.

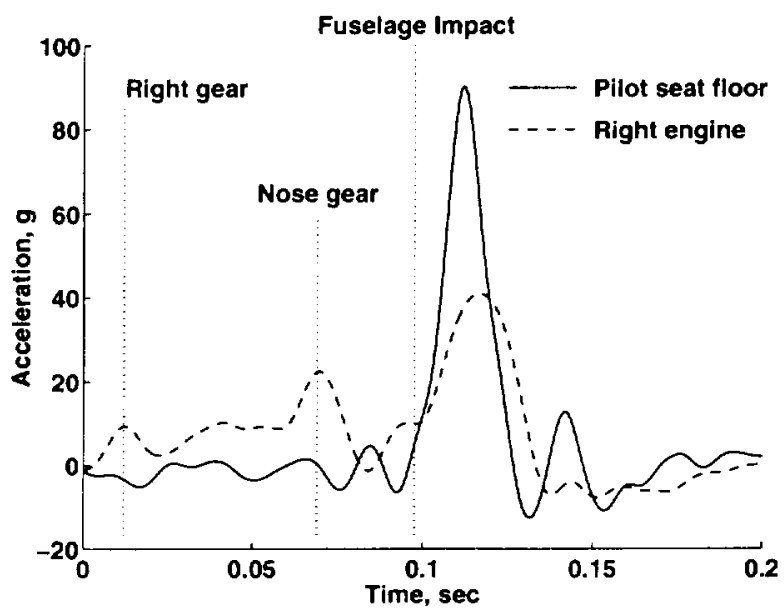

Figure 8. Representative experimental acceleration time histories for pilot seat floor and right engine locations.

For this paper, the initial velocity values at left gear contact were estimated based on the experimentally determined center-of-gravity translational and rotational velocities. The experimental velocity curves were computed by integrating the unfiltered experimental acceleration values as a function of time. Only the experimental and analytical "vertical" velocities would be compared in this paper. Note that the "vertical" velocity orientation for the simulations remained fixed with respect to the ground and was aligned with the aircraft at left gear contact. The experimental accelerometers were attached to the fuselage and thus rotated with the aircraft as the landing gear stroked. For this reason, the experimental and analytical "vertical" accelerations are aligned at $0 \mathrm{~ms}$, but the acceleration directions would differ approximately $6.25^{\circ}$ at fuselage impact. This discrepancy is not considered significant for the results presented here, since the cosine of $6.25^{\circ}$ is 0.994 , or the induced error is less than $1 \%$.

Comparisons of the two crew-seat floor attachment velocities are shown in Figures 9 and 10. Both the predicted and the measured velocities at the pilot and copilot locations show a nearly constant velocity prior to fuselage impact. This trend results from the balancing of the rotational pitch velocity component with the downward linear motion of the center-of-gravity.

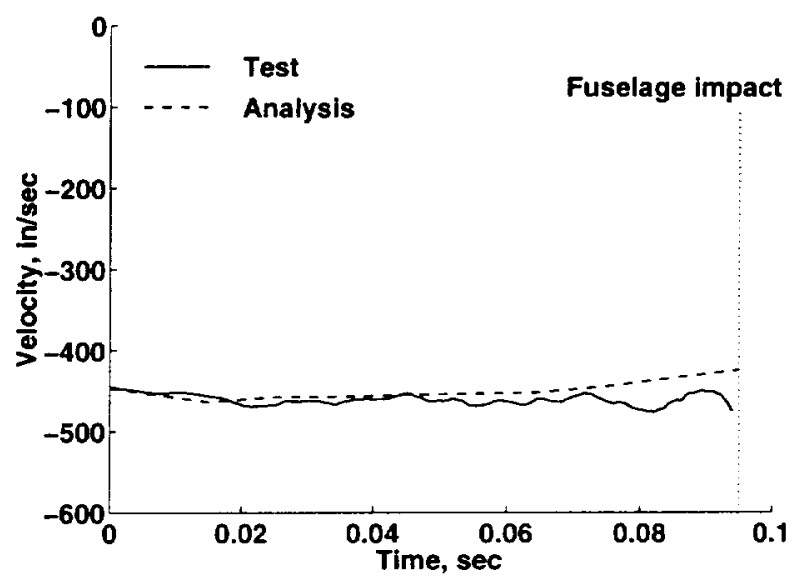

Figure 9. Comparison of experimental and analytical vertical velocities at the pilot seat floor.

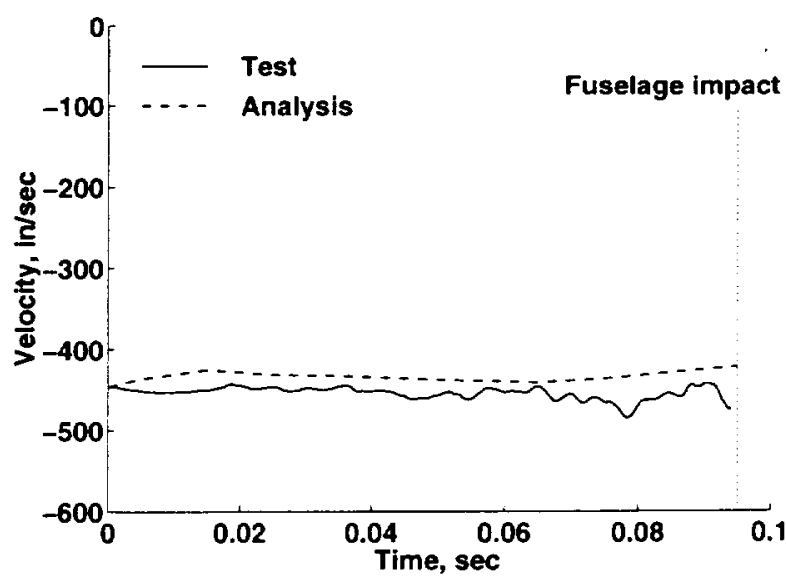

Figure 10. Comparison of experimental and analytical vertical velocities at the copilot seat floor. 
The measured and predicted velocities near the troop-seat attachment locations are shown in Figures 11 through 13. Note that for these positions, the velocity decreases approximately $100 \mathrm{in} / \mathrm{sec}$ while the landing gear strokes. The measured and predicted vertical velocities above the troop seat area and at the rotor head are shown in Figures 14 and 15 . The change in velocities is nearly $150 \mathrm{in} / \mathrm{sec}$. The close comparison of the predicted and measured values, shown in Figures 9 through15, indicates that the simplified landing gear modeling implementation and the rigid fuselage assumption are adequate up to the time of fuselage impact.

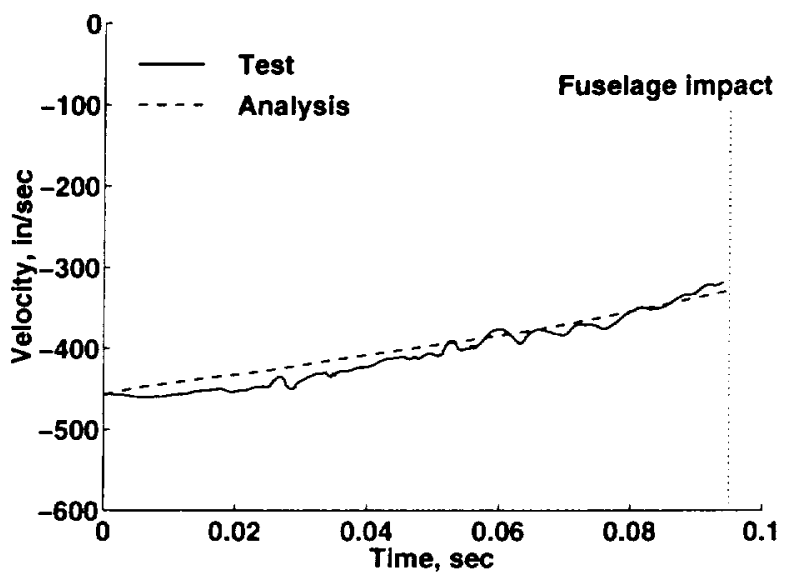

Figure 11. Comparison of experimental and analytical vertical velocities at the left troop seat floor location.

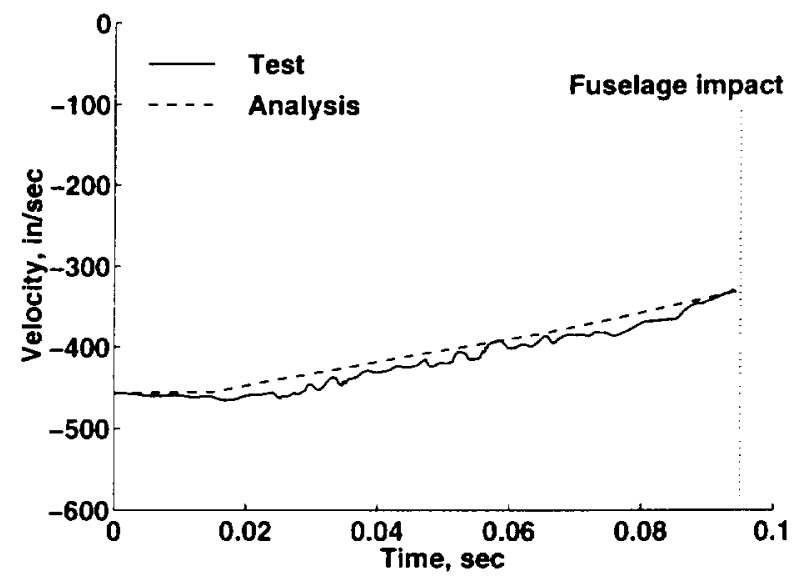

Figure 12. Comparison of experimental and analytical vertical velocities at the right troop seat floor location.

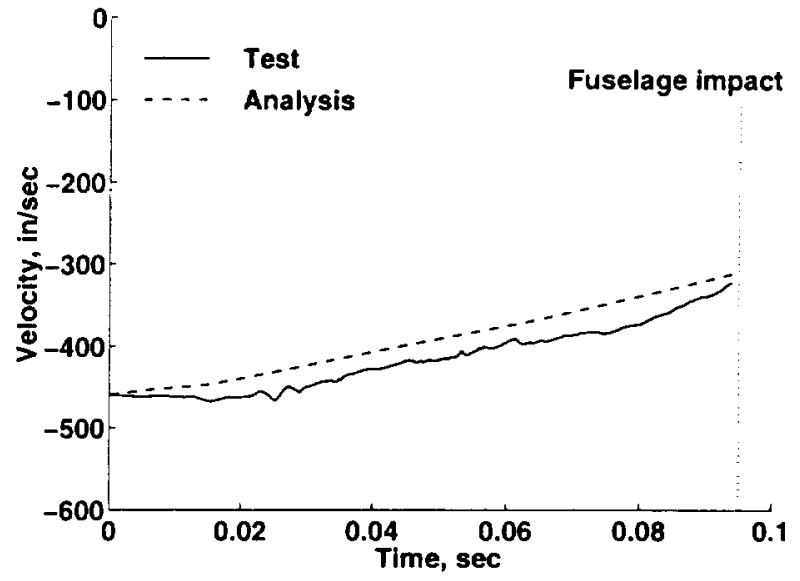

Figure 13. Comparison of experimental and analytical vertical velocities at BS182.

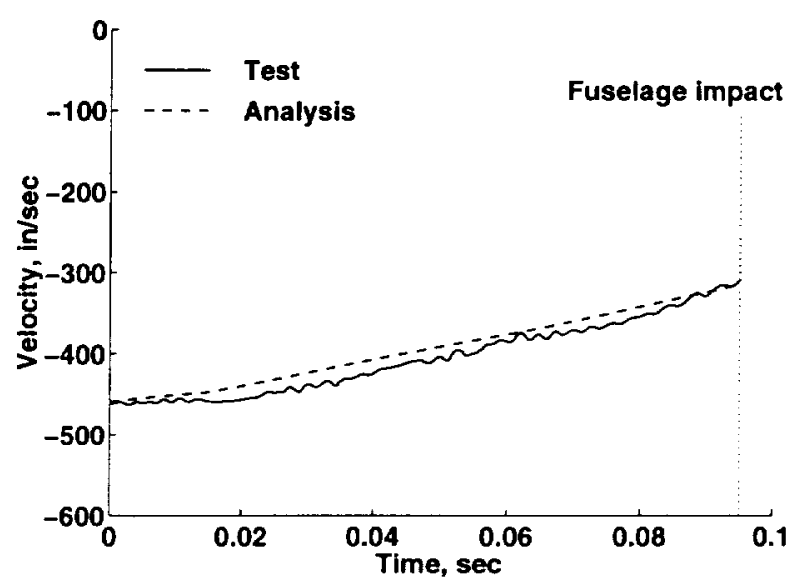

Figure 14. Comparison of experimental and analytical vertical velocities at BS188.

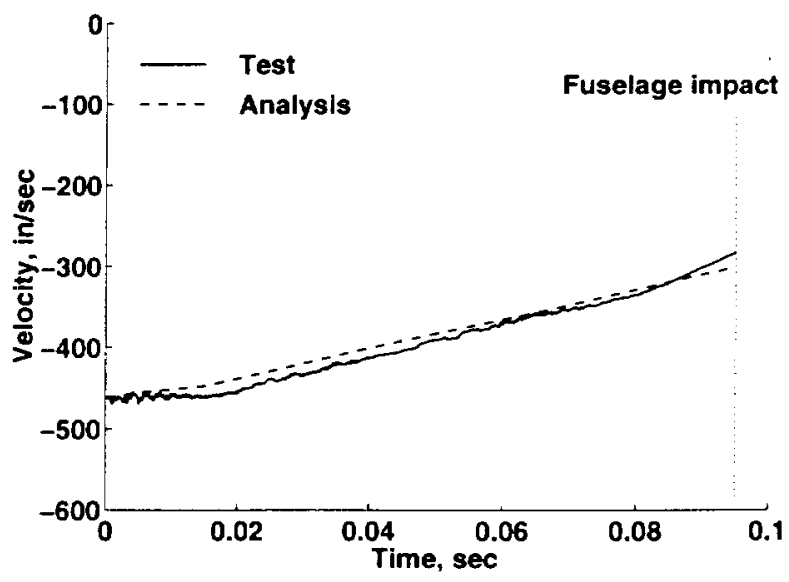

Figure 15. Comparison experimental and analytical vertical velocities at the rotor head. 
In Figures 16 through 19, comparisons of the experimental and predicted velocity responses at locations aft of the center of gravity are shown. The right landing gear attachment point is shown in Figure 16. The simulation/experimental correlation at this location is fair. The irregular trend in the experimental data results from complexities of the landing gear stroking mechanism, such as shear pin failures and the fact that the test article is attached to a flexible fuselage rather than the rigid fuselage used in the simulations. These large oscillations in the velocities are local and not transmitted to the rest of the fuselage as indicated by the absence of the oscillations in the remaining velocity curves. The right and left engine velocities are shown in Figures 17 and 18, respectively. The correlation is excellent up to nearly $0.070 \mathrm{~s}$. A similar trend is seen for the location at the top of the bulkhead at BS255, see Figure 19. A number of factors may contribute to the deviation of the simulation results from the experimental data, including violation of the rigid fuselage assumption in that the roof is beginning to collapse. In addition, the tail was determined to fail at $0.075 \mathrm{sec}$. This failure could have significantly affected the response at this portion of the fuselage.

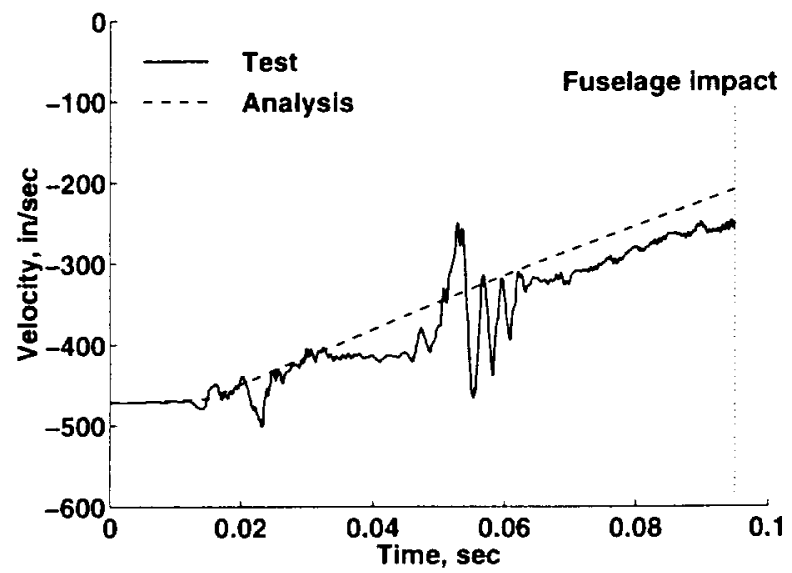

Figure 16. Comparison of experimental and analytical vertical velocities at the top of the right gear.

The accuracy of the acceleration response is directly related to the accuracy of the input energy at fuselage contact. One method to evaluate the accuracy of the impact energy is to correlate analytical and experimental squared velocities, see Figure 20 . The squared velocity values are proportional to the kinetic energy. Prior to the correlation with the test data, the rigid fuselage approach would have been assumed valid up to

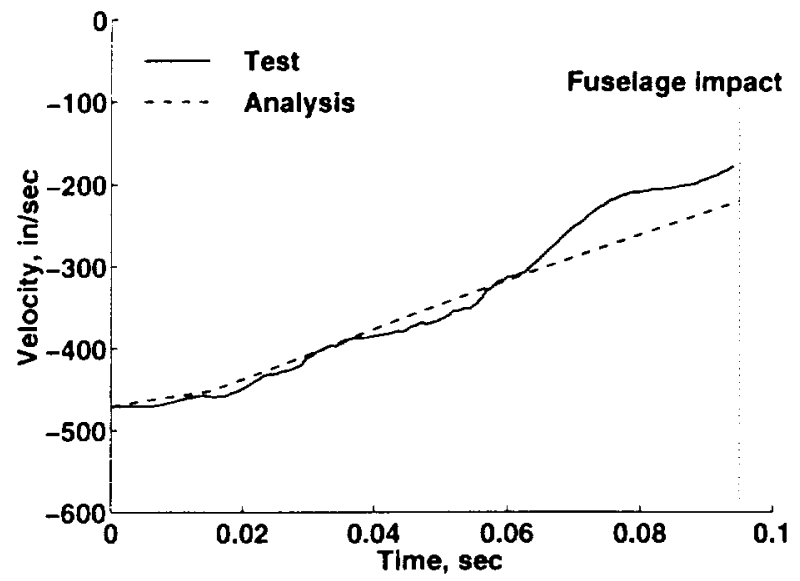

Figure 17. Comparison of experimental and analytical vertical velocities at the right engine.

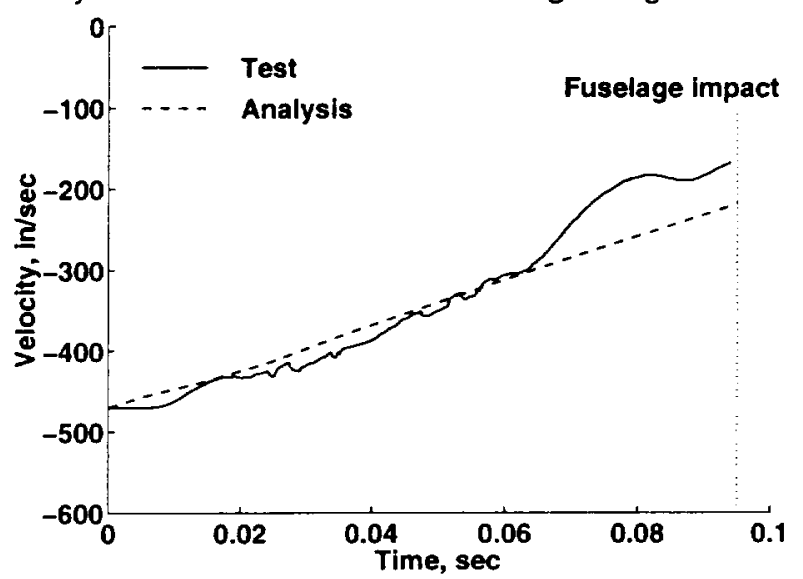

Figure 18. Comparison of experimental and vertical analytical velocities at the left engine.

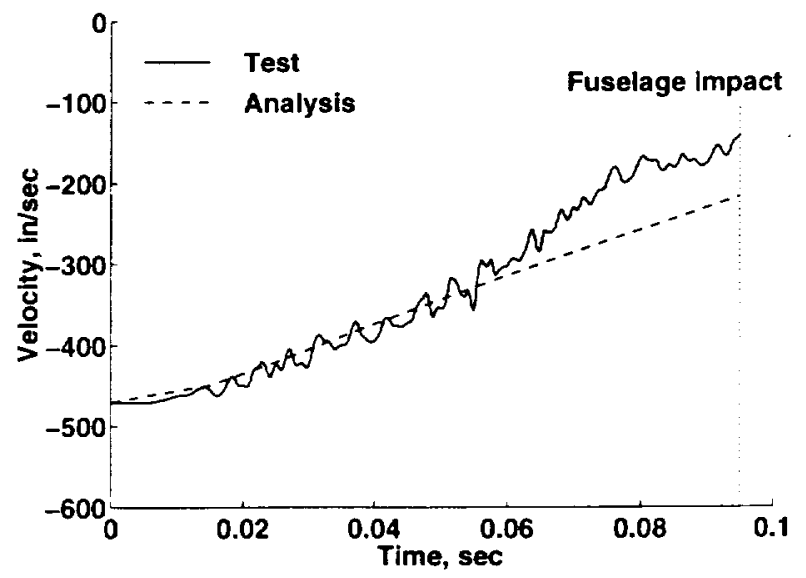

Figure 19. Comparison of experimental and analytical vertical velocities at the roof BS255.

the time of fuselage contact at $0.095 \mathrm{sec}$. However preliminary correlations of the experimental data and simulation results indicated that the flexible model should begin at $0.065 \mathrm{sec}$, or when the predicted velocities of the large masses aft of the 
center-of-gravity deviated from the experimental values. For these reasons, the accuracy of the rigid simulation results for utilization in a flexible finite element model has been evaluated based on a comparison of the experimental and analytical squared-velocity values at both 0.065 and 0.095 sec. The experimental value is used for the normalization.

At $0.065 \mathrm{sec}$, the predicted results at seven of the eleven locations are within $5 \%$ of the experimental values. The accuracies of the predicted results are within $15 \%$ at an additional three locations. The largest deviation is $23 \%$ at the Roof BS255 location. These correlation values are considered excellent.

At $0.095 \mathrm{sec}$, the predicted squared-velocities at five of the eleven locations are within $15 \%$ of the measured values. The predictions at an additional three locations are within $30 \%$. The predicted values at three of the locations vary substantially from the measured values. All of the floor locations, which would significantly affect occupant response, are within $30 \%$. The correlation between the experimental and analytical squaredvelocities forward of the center-of-gravity is fair.

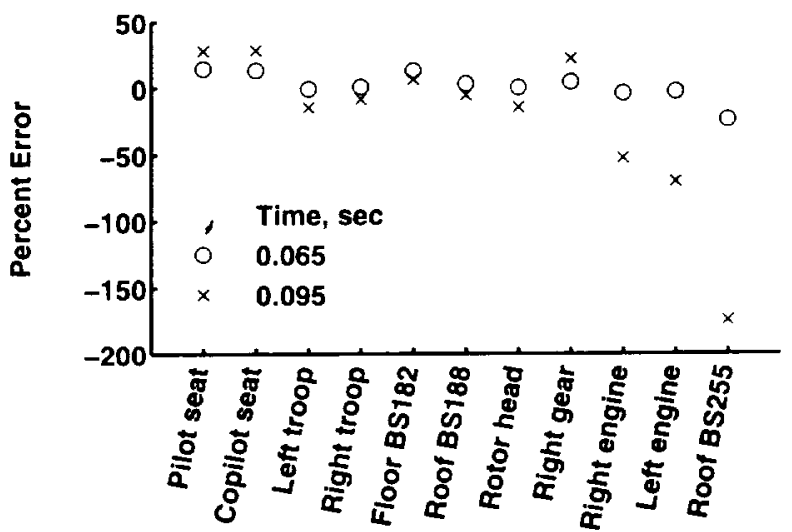

Figure 20. Error of the predicted squared-velocity at the indicated locations when compared to the experimental values $\left(\%\right.$ error $=\left[\left(V_{\text {test }}^{2}-V_{\text {pred }}^{2}\right) / V_{\text {test }}^{2}\right] x$ 100).

\section{CONCLUDING REMARKS}

An innovative and simplified landing gear modeling approach was implemented in a detailed crash simulation of a full-scale crash test of a composite helicopter. The crash simulation methodology was further simplified by utilizing the simple landing gear model with a rigid and geometrically accurate fuselage model. Helicopter crash simulations using this approach were compared with previously acquired experimental data from a full-scale crash test of a composite helicopter. The following conclusions were reached:

1) The simplified landing gear modeling approach accurately simulated the magnitude and orientation of the landing gear force on the fuselage.

2) The use of a rigid fuselage model for a portion of the crash simulation was appropriate and resulted in significant reduction of CPU-time for the total crash simulation.

In summary, the crash model was successful at approximating the effect of the landing gear stroking without adding substantially to the model complexity. This simplification in conjunction with the rigid fuselage assumption can result in significant reduction in CPU-time.

\section{REFERENCES}

1) Gamon, M.; Wittlin, G.; and LaBarge, B., "KRASH 85 User's Guide - Input/Output Format," Final Report DOT/FAA/CT-85/10, May 1985.

2) Anon, LS-DYNA3D User's Manual, Livermore Software Technology Company, Livermore, CA, 1997.

3) Anon, MSCIDYTRAN User's Manual Version 4.0, The MacNeal-Schwendler Corporation, Los Angeles, CA, November 1997.

4) PAM-CRASH, Engineering Systems International SA, F-94588 Rungis, France.

5) Anon., "ACAP Interim Technical Report, Volume III - Military Characteristics", Report No. TR17304, Sikorsky Aircraft, March 1982.

6) Boitnott, R. L., Jackson, K. E., and Fasanella, E. F., "Full-Scale Crash Test of the Sikorsky Advanced Composite Airframe Program Helicopter", Proceedings of the American Helicopter Society $56^{\text {th }}$ Forum, Virginia Beach, VA, May 2-4, 2000.

7) Fasanella, E. L., Jackson, K. E., and Lyle, K. H., "Finite Element Simulation of a Full-Scale Crash test of a Composite Helicopter", Proceedings of the American Helicopter Society $56^{\text {th }}$ Forum, Virginia Beach, VA, May $2-4,2000$.

8) Lahey, R. S., Miller, M. P., Reymond, M., "MSC/NASTRAN Reference Manual, Version 68," The MacNeal-Schwendler Corporation, Los Angeles, CA, 1994. 